\title{
Green Synthesis of Magnetic Nanoparticles by Murraya Koenigii Leaves Extract for Biomedical Application
}

Sivakami M ( $\sim$ sivahhrc2020@gmail.com )

Bharathidasan University

Renuka Devi K

Government Arts College for women, Pudukkottai

Renuka R

Government Arts College for women, Pudukkottai

\section{Research Article}

Keywords: Magnetic nanoparticles, spherical, Antimicrobial, Vibrating sample magnetometer, Antidiabetic.

Posted Date: June 4th, 2021

DOI: https://doi.org/10.21203/rs.3.rs-583600/v1

License: (c) (1) This work is licensed under a Creative Commons Attribution 4.0 International License. Read Full License 


\title{
Green synthesis of Magnetic nanoparticles by Murraya koenigii leaves extract for
}

\section{Biomedical Application}

\author{
M. Sivakami ${ }^{\text {a*, K. Renuka Devi }}{ }^{\text {b }}$, R. Renuka ${ }^{\text {b }}$ \\ ${ }^{a}$ H.H. The Rajah's College, Pudukkottai-622001, India \\ ${ }^{\mathrm{b}}$ Government Arts College for women, Pudukkottai-622001, India
}

* Corresponding author: Assistant Professor, H.H. The Rajah's College, Pudukkottai-622001, India, Siva_hhrc@yahoo.in, sivahhrc2020@gmail.com

\begin{abstract}
Green synthesis of nanoparticles is the method with eco-friendly, cost-effectiveness, and ease of resource availability approach. Nowadays, magnetic nanoparticles need increased due to its use in magnetic sensing, medical imaging, waste water treatment, and antibiotic drugs. In this report, the ecofriendly green synthesis of magnetic iron oxide nanoparticles were efficiently synthesized by using Murraya koenigii leaves extract. UV-visible spectrum revealed the surface Plasmon resonance band at $240 \mathrm{~nm}$ and analyzed the formation of iron oxide nanoparticles. Xray diffraction pattern determined its high crystalline nature with strong intense peaks. Fourier Transform Infra-Red spectrum illustrated the $\mathrm{Fe}$ and $\mathrm{O}$ bonding stretching vibration. The particle size distribution graph showed the formed particles are in nanometer range. Transmission Electron Micrographs realized the spherical shaped iron oxide nanoparticles with its size at 10$25 \mathrm{~nm}$. The energy dispersive X-ray spectrum and mapping analysis revealed the purity of prepared nanoparticles with only $\mathrm{Fe}$ and $\mathrm{O}$ presence. The vibrating sample magnetometer analysis showed the paramagnetic behavior of prepared magnetic iron oxide nanoparticles. The antimicrobial assay revealed potent inhibition of iron oxide nanoparticles on various human pathogens. The antioxidant, anti-inflammatory and anti-diabetic assays revealed the biomedical behavior of iron oxide nanoparticles.
\end{abstract}


Keywords: Magnetic nanoparticles; spherical; Antimicrobial; Vibrating sample magnetometer; Anti-diabetic.

\section{Introduction}

Nanoparticles (NPs) with dimension in 1 to $100 \mathrm{~nm}$ have specific physical, chemical and biological properties. Nanotechnology provides its tremendous growth on all fields such as optic, electronic, textile, agricultural, environmental, and biomedical etc., [1] Nanoparticles have enormous applications with peculiar large surface to volume ratio property and enhanced efficiency in all fields in the form of catalysts, batteries, solar cells, gas sensors, LEDs, semiconductors, glasses, sunscreen products, cosmetics, building materials, leathers, food packaging, cloths and drugs etc. [2,3], The manipulation of nanoparticles are one of the interesting research area for researchers which is necessitating field for the existence world. Because, it formed simple to complicate networks that are imperative to materials science [4]. Nowadays, treating diseases and infections is becoming tough to the clinical field. The infectious strains are easily spread and cause huge health crisis and problem to humans and animals. Some pathogenic strains are not responding to antimicrobial agents and create huge damage to human health system [5]. Bio nanotechnology involves the production, operation and implementation process of drugs to several human and animal diseases. It can able to create antibiotic drugs against human pathogens without producing any side effects. In clinical field, bio nanotechnology plays a vital role for finding drugs to cure life threatening diseases [6].

In this peculiar nanotechnology, particles were synthesized by various physical, chemical and biological methods. The physical and chemical methods produce nanoparticles with polluting by-products. It can create harm to environment and organisms [7,8]. The nanoparticles requiring toxic reducing agents must produce harmful by-products which create pollution to 
environment and affect living organisms. But, in biosynthesis, it must be reduced by using plant materials, bacteria or fungi, yeasts and agricultural wastes. It does not require high energy, pressure, cost, and hazardous chemicals. It does not produce any toxic to environment [9]. Further, green synthesis of nanoparticles using plant extracts is an easy, cost-effectiveness, ease of resource availability and large productive approach comparing to other biological methods. The eco-friendly synthesis of nanoparticles has practical applications in clinical, biomedical, agricultural, and drug delivery fields as drugs without producing any side effects [10].

Among green synthesized nanoparticles, inorganic nanoparticles have peculiar interest to researchers due its ease availability and necessity [4]. It has many practical applications viz., sunscreen glasses and products, cosmetics, sensors, catalysts, food packaging, paints, ceramics, batteries, and drugs [11]. With this, magnetic NPs attain interest towards research with their high catalytic, intrinsic, and versatile properties. It is used in vast field's viz., food, biosensing, medical and magnetic separation, degradation of organic pollutants, and waste water treatment [12]. Iron oxide NPs are mostly used in dye remover for preserving pollution free environment [5]. Mostly, iron oxide NPs are used as biosensor and magnetic field assisted drug delivery therapy in clinical field.

Reports in green synthesis of magnetic NPs using different plant extracts and some of them are; Cymbopogon citratus [13], Carica papaya [14], Laurus nobilis [15], Platanus orientalis [16], Amaranthus spinosus [17], Pinus pinaster [18], Moringa oleifera [19], Eucalyptus [20], Rosemary [21], Mangifera indica [22], Camellia sinensis [23], Daphne mezereum [5], Vitex negundo [24], Terminalia bellirica [19], and Psoralea corylifolia [25].

Murraya koenigii is native to India, and they are used for both medicinal and culinary applications. They are highly aromatic and have a unique citrus flavor. Aside from being a 
versatile culinary herb, they offer an abundance of health benefits due to the powerful plant compounds they contain. Curry leaves are rich in alkaloids, glycosides, and phenolic compounds that give potent health benefits. Most of them function as antioxidants in our body. Antioxidants play an indispensable role in maintaining our body healthy and free from diseases. Curry leaves are the good sources of iron and calcium. Due to this reason, they are used as medicine to treat calcium deficiency. It is also used to reduce blood glucose levels effectively. They offer shield to insulin producing cells and avoid harm caused by free radicals [26]. Traditionally, curry leaves are assumed to have favorable effect for eyesight. It can be used to prevent early onset of cataract. Most illness is initiated by infections or oxidative damage in the body. Curry leaves can be used as an alternative and natural treatment for such infections. Curry leaves contains carbazole alkaloids which are compounds with antibacterial, anti-inflammatory, antioxidant and anticancer properties [26,27].

This is the first time reporting ecofriendly synthesis of magnetic iron oxide NPs by Murraya koenigii leaves extract from the literature survey. The prepared magnetic iron oxide NPs were studied by various analytical techniques for realizing its spectral, optical, morphological, elemental, magnetic and biological properties.

\section{Materials and Methods}

\subsection{Chemicals Used}

Ferric chloride $\left(\mathrm{FeCl}_{3}(\geq 98.99 \%)\right)$, ethanol ( $\left.\geq 99.92 \%\right)$, deionized water and Murraya koenigii leaves collected from Pudukkottai were used. All the chemicals used were purchased from Sigma Aldrich, India.

\subsection{Murraya koenigii leaves extract preparation}


$5 \mathrm{~g}$ of Murraya koenigii fresh healthy leaves were taken and thoroughly cleaned with tap water and deionized water. The leaves were immersed in $100 \mathrm{~mL}$ of ethanol and heated on a magnetic stirrer to $80{ }^{\circ} \mathrm{C}$ for $30 \mathrm{~min}$. After reaching the room temperature, the solution was filtered with Whatman No.1 filter paper to remove the residual impurities. The filtered Murraya koenigii leaves extract solution was preserved at $4{ }^{\circ} \mathrm{C}$ in a refrigerator for further use.

\subsection{Synthesis of iron oxide NPs by Murraya koenigii leaves extract}

About $0.1 \mathrm{M}$ of $\mathrm{FeCl}_{3}$ was dissolved in $90 \mathrm{~mL}$ of deionized water by continuous stirring on a magnetic stirrer. Then, $10 \mathrm{~mL}$ of Murraya koenigii leaves extract was taken in burette and mixed into ferric chloride solution by drop wise. The solution was heated to $70{ }^{\circ} \mathrm{C}$ for $2 \mathrm{~h}$ with continuous stir. The brown color solution turned into black. It indicates the formation of iron oxide NPs. The dark brownish black precipitate was washed with deionized water and dried at 80 ${ }^{\circ} \mathrm{C}$ in a hot air oven. Then, the iron oxide NPs was preserved and analyzed by various analytical techniques. The synthesis scheme was revealed in Figure (1).

\subsection{Characterization of iron oxide NPs}

The prepared iron oxide NPs were characterized using various analytical techniques. UVvisible analysis was completed by UV-DRS spectrophotometer Thermofisher Evaluation 220. Xray powder diffraction (XRD) analysis was recorded with the help of PANalytical X'Pert PRO powder X-ray diffractometer in a scan rate at $10^{\circ}$ to $80^{\circ}$. Fourier Transform Infra-Red spectrum was recorded using Thermo Nicolet 380 FTIR spectrometer at $4000-400 \mathrm{~cm}^{-1}$. The particle size distribution analysis (Dynamic Light Scattering-DLS) was studied by Particle size analyzer. The morphology of prepared sample was analyzed using JEOL-2100+ High-Resolution Transmission Electron Microscope. The elemental and mapping analyses was taken from Energy Dispersive X-ray Spectrometer Quantax 200 with X Flash ${ }^{\circledR ~ 6130 . ~ T h e ~ p h y t o c h e m i c a l ~ a n a l y s i s ~ w a s ~ c a r r i e d ~}$ 
out as in earlier report [28]. The magnetic property of prepared sample was studied from vibrating sample magnetometer (VSM) by Microsense model ADE-EV9, applying $2.2 \mathrm{~T}$ magnetic fields in a room temperature.

\subsection{Antimicrobial Assay}

Antimicrobial assay was completed through well plate method using microtitre plate [28]. LB broth and taken microbial cells (Pseudomonas aeruginosa, Acinetobacter baumannii, Serratia marcescens, Chromobacterium violaceum, Enterobacter aerogenes, Klebsiella penumonia (Gram-negative bacterial cells), Enterococcus faecalis, Staphylococcus aureus (Gram-positive bacterial cells), Candida albicans, Candida tropicalis, Aspergillus niger, and Aspergillus flavus (fungus cells)) were utilized as a growth medium. The analysis performed by 96 microtitre plates containing full of growth medium and taken microbial inoculums with prepared sample in varied concentrations viz., 5, 10, 25, 50, 100, and $150 \mu \mathrm{g} / \mathrm{mL}$. Similarly, positive control as Chloramphenicol was treated. Without sample and positive control was treated as control. Then, the plates were put at $37{ }^{\circ} \mathrm{C}$ for $24 \mathrm{~h}$. The analysis was studied in triplicate times. After, it was analyzed with UV-spectrophotometer. The changes in absorbance were noted for calculating percentage of inhibition by,

$$
\text { Antimicrobial assay }(\%)=\left[\left(A_{c}-A_{S}\right) / A_{c}\right] \text { X } 100
$$

Where, $\quad \mathrm{A}_{\mathrm{c}}=$ Control absorbance, $\mathrm{A}_{\mathrm{s}}=$ Sample absorbance.

\subsection{Antioxidant Assay}

Antioxidant assay was completed as in earlier report [29]. $0.5 \mathrm{~mL}$ of prepared NPs solution was taken and separated into varied concentrations viz., 20, 40, 60, and $80 \mu \mathrm{g} / \mathrm{mL}$. It was mingled with $2 \mathrm{~mL}$ of $\mathrm{DPPH}$ methanol solution. The reaction mixture solution was continuously stirred for $30 \mathrm{~min}$. Then, it was put in a dark area at room temperature. After 30 
min, it was analyzed by UV-visible spectrophotometer and the absorbance was recorded. Similarly, the positive control of ascorbic acid was treated. The assay was performed in triplicate times.

$$
\text { Antioxidant assay }(\%)=100-\left[\left(\mathrm{A}_{\mathrm{c}}-\mathrm{A}_{\mathrm{s}}\right) / \mathrm{A}_{\mathrm{c}}\right] \text { x } 100----(2)
$$

Where, $\quad \mathrm{A}_{\mathrm{c}}=$ Control absorbance, $\mathrm{A}_{\mathrm{s}}=$ Sample absorbance.

\subsection{Anti-inflammatory Assay}

Anti-inflammatory assay was investigated by the method followed as in earlier report [29]. At first, $2.8 \mathrm{~mL}$ of phosphate-buffered saline (PBS) (pH 6.4), $0.2 \mathrm{~mL}$ of bovine serum albumin was taken and mixed with prepared NPs sample solution of $2 \mathrm{~mL}$ in varied concentration viz., 100, 200, 300, 400, and $500 \mu \mathrm{g} / \mathrm{mL}$. After, the reaction mixture solution was incubated at $37 \pm 2{ }^{\circ} \mathrm{C}$. After completing $15 \mathrm{~min}$, it was heated to $70{ }^{\circ} \mathrm{C}$. The absorbance was recorded from UV-visible spectrophotometer, when the solution reached to room temperature. Similarly, positive control of Diclofenac sodium was treated. The assay was performed in triplicate times.

$$
\begin{aligned}
& \text { Anti-inflammatory assay } \left.(\%)=100-\left[\left\{V_{c}-V_{t}\right\} / V_{c}\right\}\right] \times 100 \\
& \text { Where, } \quad \mathrm{V}_{\mathrm{c}}=\text { Control absorbance, } \quad \mathrm{V}_{\mathrm{t}}=\text { Sample absorbance. }
\end{aligned}
$$

\subsection{Anti-diabetic Assay}

Anti-diabetic assay was investigated by the method followed as in earlier report [29]. At first, $0.5 \mathrm{mg} / \mathrm{mL}$ of $\alpha$-Amylase was maintained at $25{ }^{\circ} \mathrm{C}$ for $10 \mathrm{~min}$. The prepared NPs solution of $2 \mathrm{~mL}$ was taken in varied concentrations viz., 100, 200, 300, 400, and $500 \mu \mathrm{g} / \mathrm{mL}$ and mingled to starch solution. $20 \mathrm{mM}$ of sodium phosphate $(\mathrm{pH}$ 6.9) and $6 \mathrm{mM}$ of sodium chloride were also mingled to sample solution. Then, it was mixed to $\alpha$-Amylase solution. The reaction mixture solution was maintained at $25{ }^{\circ} \mathrm{C}$ for $30 \mathrm{~min}$. In this solution, di-nitrosalicylic acid was mingled 
in order to view the color change. Further, the reaction mixture solution was heated to $70{ }^{\circ} \mathrm{C}$ for 5 min. Then, the absorbance was recorded from UV-visible spectrophotometer to calculate the percentage of inhibition. Similarly, positive control of acarbose was treated.

The assay was performed in triplicate times.

Anti-diabetic assay $\left.(\%)=100-\left[\left\{V_{c}-V_{t}\right\} / V_{c}\right\}\right] \times 100$

Where, $\quad \mathrm{V}_{\mathrm{c}}=$ Control absorbance, $\quad \mathrm{V}_{\mathrm{t}}=$ Sample absorbance.

\section{Results and Discussion}

In this report, the iron oxide NPs were green synthesized with Murraya koenigii leaves extract. The green synthesis was the method with eco-friendly, cost-effectiveness and it avoided the production of hazardous by-products. The formation of iron oxide NPs was confirmed with visual observation of brownish black color change appeared in synthesis. The phytochemicals in Murraya koenigii leaves extract played capping and stabilizing agents in the formation of iron oxide NPs. The phytochemicals in Murraya koenigii leaves extract were analyzed via two ways viz., alcoholic and aqueous extractive method. In this, alcoholic extract provided favorable phytochemicals. Then, the synthesis was done in alcoholic extractive method. The phytochemicals in Murraya koenigii leaves extract were listed in Table 1. The greener way mediated iron oxide NPs were characterized by various analytical techniques for understanding its optical, structural, elemental and biological properties.

\subsection{Characterization of Iron Oxide NPs}

UV-visible spectrum of prepared iron oxide NPs was exposed in Figure (2a). The surface Plasmon resonance band was observed at $240 \mathrm{~nm}$. It confirms the formation of iron oxide NPs and it comparable with earlier report [30]. Rajendran et al. [30] reported iron oxide NPs using Sesbania grandiflora leaf extract have its SPR band at $220 \mathrm{~nm}$. 
XRD pattern of prepared iron oxide NPs was shown in Figure (2b). The strong and intense peaks at $36.09^{\circ}, 41.87^{\circ}, 60.72^{\circ}, 72.74^{\circ}$, and $76.54^{\circ}$ and their corresponding planes (111), (200), (220), (311), and (222) represent the high crystalline formation of iron oxide NPs. The pattern was harmonized with JCPDS no. 772355. The average crystallite size was calculated at $14 \mathrm{~nm}$ from Scherer's formula. Kanagasubbulakshmi et al. reported iron oxide NPs using Lagenaria Siceraria have its crystallite size at 14-18 nm [31]. The lattice strain calculated was at 0.0039 . The dislocation density calculated was at $7.815 \times 10^{15} \mathrm{~m}^{-2}$ by,

$$
\delta=1 / D^{2}
$$

The microstrain found was at $5.030 \times 10^{-3}$ by [32],

$$
\varepsilon=\beta \cos \theta / 4 \quad---(6)
$$

The high crystalline and small size of iron oxide NPs was attained by using Murraya koenigii leaves extract.

FT-IR spectrum of prepared iron oxide NPs was revealed in Figure (2c). The bands recorded at $3454,2427,1767,1637,1384,1112,831,537$, and $459 \mathrm{~cm}^{-1}$. The band at $3454 \mathrm{~cm}^{-1}$ may be due to $\mathrm{OH}$ stretching vibration of hydroxyl or phenolic group. The band at $2427 \mathrm{~cm}^{-1}$ corresponds to aromatic aldehyde group of $\mathrm{C}-\mathrm{H}$ stretching vibration whereas the band at 1767 $\mathrm{cm}^{-1}$ may be due to ester group of $\mathrm{C}=\mathrm{O}$ stretching vibration [33]. The band at $1637 \mathrm{~cm}^{-1}$ denotes the amino acid stretching vibration whereas the band at $1384 \mathrm{~cm}^{-1}$ represents the germinal methyl group stretching vibration [28]. The band at $1112 \mathrm{~cm}^{-1}$ corresponds to carboxylic group stretching vibration [29]. The bands at 831,537 , and $459 \mathrm{~cm}^{-1}$ represents the Fe-O stretching vibration. Generally, the bands below $1000 \mathrm{~cm}^{-1}$ denoted the metal oxygen bonding stretching vibration [32]. The phytochemicals in Murraya koenigii leaves extract played a vital role in capping and stabilizing process of prepared iron oxide NPs that present on the surface of free Fe 
[12]. It was clearly understood from the other vibrational group presence in FT-IR rather than Fe-O stretching vibration.

DLS analysis was carried out to observe the particle size distribution and it was shown in Figure (2d). The particle size distribution spectrum gives the prepared iron oxide NPs was at 7$15 \mathrm{~nm}$. It was further confirmed by TEM particle size measurement. Comparing with TEM analysis, the particle size observed in DLS was greater than it. It was appeared due to the measurement in hydrodynamic size. The polydispersity index (PDI) was obtained at 0.298. It intimates the prior indication of potential application in drug delivery and bio-medical fields [34].

The magnetization curve of prepared iron oxide NPs was revealed in Figure (2e). The paramagnetic behavior of prepared iron oxide NPs was found from no hysteresis loop containing linear magnetization versus applied magnetic field $(\mathrm{M}-\mathrm{H})$ curve. The green synthesized iron oxide NPs was weakly attracted by strong magnetic field (B) and formed internal induced magnetic field in that applied direction $[22,35]$.

TEM analysis was carried out to view the morphology of prepared iron oxide NPs and its graphs were displayed in Figure (3a-b). The spherical shaped [36] iron oxide NPs was observed and its size ranges from 8-12 $\mathrm{nm}$. Some region seems to be agglomerated due to the usage of Murraya koenigii leaves extract in synthesis (plant extract). Arsalani et al. synthesized iron oxide NPs by natural rubber latex and reported its size at 7-15 nm with spherical shape [37]. Jamzad et al. prepared iron oxide NPs by Laurus nobilis leaves extract and reported its size at 8-10 nm with spherical shape [15]. Figure (3c) revealed the selected area electron diffraction (SAED) pattern of iron oxide NPs. The polycrystalline formation of iron oxide NPs was understood from the white spots in black area (SAED pattern). The d-spacing of (200) lattice plane in XRD was well 
matched with SAED d-spacings measurement. It also further confirmed the formed NPs were iron oxide. The EDS spectrum of iron oxide NPs was shown in Figure (4). It confirmed the presence of iron $(\mathrm{Fe})$ and oxygen $(\mathrm{O})$ in the synthesized NPs. The low carbon (C) signal was present due to the plant extract $[28,32]$. The atomic and weight percentages of $\mathrm{Fe}, \mathrm{O}$ and $\mathrm{C}$ are displayed in Figure (4). The EDS spectrum was further analyzed with mapping analysis which is revealed in Figure (5). It also shows the iron, oxygen and carbon presence in NPs with red, green and blue spots.

\subsection{Biomedical Applications}

\subsubsection{Antimicrobial Assay}

The antimicrobial analysis was a preliminary investigation in bio-medical field to understand the antibiotic behavior against human pathogens with the reason of microbial pathogens cause huge health crisis in the world. In this analysis, the prepared iron oxide NPs was tested on various human pathogens such as Pseudomonas aeruginosa, Acinetobacter baumannii, Serratia marcescens, Chromobacterium violaceum, Enterobacter aerogenes, Klebsiella penumonia (Gram-negative bacterial cells), Enterococcus faecalis, Staphylococcus aureus (Gram-positive bacterial cells), Candida albicans, Candida tropicalis, Aspergillus niger, and Aspergillus flavus (fungus cells). The analysis was studied through Agar well diffusion method. The various concentrations such as $5,10,25,50,100$, and $150 \mu \mathrm{g} / \mathrm{mL}$ were applied for finding antibacterial potency of prepared NPs. Chloramphenicol was set as positive control. The Gramnegative bacterium was more pathogenic than Gram-positive bacterium [38]. Then, the analysis was studied mostly on Gram-negative bacterial cells. The fungus cell has much stronger cell wall structure than fungus cell. Therefore, analysis was also investigated in fungus cells to knowing NPs potency. The tested microbes produced many dreadful infections and they present in soil, 
water, and air medium. They mainly exist in dirt, hospital, drainage and unhygienic zones [29]. The inhibition of microbial cells by iron oxide NPs were expressed as percentage in Figure (6) and taken in triplicate times.

On the tested microorganisms, Pseudomonas aeruginosa, Enterobacter aerogenes, Klebsiella penumonia, Chromobacterium violaceum were more susceptible at $100 \mu \mathrm{g} / \mathrm{mL}$. Acinetobacter baumannii, Serratia marcescens, Enterococcus faecalis, Staphylococcus aureus, Candida albicans, Candida tropicalis, Aspergillus niger, and Aspergillus flavus were susceptible at $25 \mu \mathrm{g} / \mathrm{mL}$. Gram-positive bacteria were much inhibited than Gram-negative and it comparable with Premanathan et al [39]. The high concentration of iron oxide NPs used in analysis has higher inhibition on microbial cells and it harmonized with Sangeetha et al [40]. These results proved the synthesized iron oxide NPs has antibiotic behavior on the various human pathogens.

The process of inhibition of microbial cells by iron oxide NPs was as follows:

The generation of reactive oxygen species such as hydrogen peroxide $\left(\mathrm{H}_{2} \mathrm{O}_{2}\right)$, superoxide ions $\left(\mathrm{O}_{2}^{2-}\right.$ ions $)$, free radicals, $\mathrm{Fe}^{2+}$ ions and its attachment on microbial cell wall leads to rupturing of cell wall structure. Also, the electrostatic attraction between iron oxide NPs and microbial cells prompt the cell wall damage. It caused the release of cytoplasmic ingredients from the cell. Then, ROS easily penetrated into it and inhibit the DNA nuclei of cell. It leads to cell decay and it prompts the cell damage and death $[29,32,38]$.

\subsubsection{Antioxidant Assay}

The antioxidant assay of prepared iron oxide NPs is displayed in Figure (7a). Antioxidants are the essential agents for human to attain stable functioning of health system. They are rich in fruits, nuts, essential oils and vegetables. Free radicals contain unpaired electrons and easily attach nearby molecule to attain stable. They are produced in human body to 
systemize immune function, chemical signaling, energy supply and detoxification [17]. The assay was carried out with various concentrations such as $20,40,60,80$ and $100 \mu \mathrm{g} / \mathrm{mL}$. Ascorbic acid was set as positive control. The results were expressed as percentage in Figure and taken in triplicate times which values were listed in Table 2.

The percentage of inhibition by iron oxide NPs and ascorbic acid were 24.04, 45.17, $67.19,80.06,91.17 \%$ and $20.06,40.15,59.12,75.27,85.19 \%$ with $20,40,60,80$ and $100 \mu \mathrm{g} / \mathrm{mL}$ concentrations respectively. The high concentration of NPs has higher inhibition percentage. In all concentrations, NPs have higher inhibition percentage than positive control.

$\mathrm{IC}_{50}$ value represents the quantity of sample needed to attain $50 \%$ inhibition. It denotes the potency of sample. Low $\mathrm{IC}_{50}$ value symbolizes the efficient behavior of sample.

The $\mathrm{IC}_{50}$ value for iron oxide NPs and ascorbic acid was at 42 and $49 \mu \mathrm{g} / \mathrm{mL}$ respectively.

The results proved the potential behavior of prepared iron oxide NPs and comparable with earlier reports $[17,28]$.

\subsubsection{Anti-inflammatory Assay}

The anti-inflammatory assay of synthesized iron oxide NPs was revealed in Figure (7b). It is an interesting analysis to show protective behavior of sample than other destroying analyses. The fragmentation of secondary and tertiary protein structures caused loss of biological function [41]. The assay was carried out with assorted concentrations such as 100, 200, 300, 400 and 500 $\mu \mathrm{g} / \mathrm{mL}$. Diclofenac sodium was set as positive control. The results were expressed as percentage in Figure and taken in triplicate times which values were listed in Table 3.

The percentage of inhibition by iron oxide NPs and diclofenac sodium were 24.04, 45.27, 57.30, 70.04., 89.12\% and 19.04, 39.47, 51.02., 64.17, 79.99\% with 100, 200, 300, 400 and 500 
$\mu \mathrm{g} / \mathrm{mL}$ concentrations respectively. The high concentration of NPs has higher inhibition percentage. In all concentrations, NPs have higher inhibition percentage than positive control.

The $\mathrm{IC}_{50}$ value for iron oxide NPs and diclofenac sodium was at 247 and $293 \mu \mathrm{g} / \mathrm{mL}$ respectively.

The results proved the potential behavior of prepared iron oxide NPs and comparable with earlier reports $[29,41]$.

\subsubsection{Anti-diabetic Assay}

The anti-diabetic assay of prepared iron oxide NPs was revealed in Figure (7c). It is a preliminary analysis to show the sample has anti-diabetic potency. Free radical caused the oxidative damage and resists the enzyme such as $\alpha$-Amylase, $\alpha$-Glucosidase. These enzymes cause diabetics. In this analysis, $\alpha$-Amylase was used. It is an enzyme, which present in saliva and pancreas. It played vital role in glycogen and starch conversion from carbohydrates. Further, it rehabilitated into oligosaccharides from $\alpha$-D(1,4) glycosidic bonds [28]. Earlier report [42] said that, diabetes can be efficiently healed by plant material and green synthesized NPs have efficient results in curing diabetes than chemically prepared NPs without any side effects. The assay was carried out with various concentrations such as 100, 200, 300, 400 and $500 \mu \mathrm{g} / \mathrm{mL}$. Acarbose was set as positive control. The results were expressed as percentage in Figure and taken in triplicate times which values were listed in Table 3.

The percentage of inhibition on $\alpha$-Amylase by iron oxide NPs and acarbose were 24.93, $35.19,45.06,59.37,75.06 \%$ and $19.12,29.04,37.17,49.93,69.99 \%$ with $100,200,300,400$ and $500 \mu \mathrm{g} / \mathrm{mL}$ concentrations respectively. The high concentration of NPs has higher inhibition percentage. In all concentrations, NPs have higher inhibition percentage than positive control. 
The $\mathrm{IC}_{50}$ value for iron oxide NPs and diclofenac sodium was at 330 and $397 \mu \mathrm{g} / \mathrm{mL}$ respectively.

The results proved the potency of prepared iron oxide NPs and comparable with earlier reports $[28,42]$.

\section{Conclusion}

Conclusion of this article, the eco-friendly green synthesis of iron oxide NPs was efficiently performed by using Murraya koenigii leaves extract. The synthesized iron oxide NPs were characterized by various analytical techniques such as UV, XRD, FT-IR, DLS, TEM, and EDS analyses. UV analysis confirmed the formation of iron oxide NPs with SPR band at 240 nm. XRD pattern proved the high crystalline formation of iron oxide NPs with strong and intense peaks. FT-IR analysis confirmed the metal oxygen bonding functional group vibration. DLS spectrum confirmed the formed particle was in nano meter range. TEM graphs confirmed the

formed NPs were in spherical shape with size in 10-25 nm. EDS spectrum with its mapping proved the iron, oxygen presence in formed NPs. VSM analysis proved the paramagnetic behavior of NPs. The biomedical applications such as antimicrobial, antioxidant, antiinflammatory and anti-diabetic assays were performed. The antimicrobial assay proved the potency inhibition of iron oxide NPs on various human pathogens. The antioxidant, antiinflammatory and anti-diabetic assays proved the iron oxide NPs have biomedical behavior. With these results, the prepared iron oxide NPs by using Murraya koenigii leaves extract will be utilized as antibiotic drug and pesticides in biomedical and agricultural fields in future.

\section{Conflict of Interest}

The authors have no conflict of interest to declare.

\section{References}


1. S. Arokiyaraj, M. Saravanan, N.U. Prakash, M.V. Arasu, B. Vijayakumar, S. Vincent, Mater. Res. 48(9), 3323 (2013)

2. K. Mathiyalagan, A. Ponnaiah, K. Karuppiah, S. Rengapillai, S. Marimuthu, Ionics 26(8), $3929(2020)$

3. M. Kouthaman, K. Kannan, P. Arjunan, T. Meenatchi, R. Subadevi, M. Sivakumar, Mater. Lett. 276, 128181 (2020)

4. K.M. Kumar, B.K. Mandal, K.S. Kumar, P.S. Reddy, B. Sreedhar, Spectrochim. Acta A. 102, $128(2013)$

5. N. Beheshtkhoo, M.A.J. Kouhbanani, A. Savardashtaki, A.M. Amani, S. Taghizadeh, Appl. Phys. A 124(5), 1 (2018)

6. V.V. Makarov, S.S. Makarova, A.J. Love, O.V. Sinitsyna, A.O. Dudnik, I.V. Yaminsky, N.O. Kalinina, Langmuir 30(20), 5982 (2014)

7. Y. Orooji, R. Mohassel, O. Amiri, A. Sobhani, M. Salavati-Niasari, J. Alloys Compd. 835, $155240(2020)$

8. M. Nasrollahzadeh, S.M. Sajadi, A. Rostami-Vartooni, J. Colloid Inter. Sci. 459, 183 (2015)

9. B. Khodadadi, M. Bordbar, M. Nasrollahzadeh, J. Colloid Inter. Sci. 493, 85 (2017)

10. M. Nasrollahzadeh, S.M. Sajadi, A. Rostami-Vartooni, S.M. Hussin, J. Colloid Inter. Sci. 466, 113 (2016)

11. M. Sivakami, R. Renuka, T. Thilagavathi, J. Environ. Chem. Eng. 8(5), 104420 (2020)

12. S. Venkateswarlu, Y.S. Rao, T. Balaji, B. Prathima, N.V.V. Jyothi, Mater. Lett. 100241 (2013) 
13. D. Patiño-Ruiz, L. Sánchez-Botero, L. Tejeda-Benitez, J. Hinestroza, A. Herrera, Environ. Nanotechnol. Monit. Manag. 14, 100377 (2020)

14. M.S.H. Bhuiyan, M.Y. Miah, S.C. Paul, T.D. Aka, O. Saha, M.M. Rahaman, M. Ashaduzzaman, Heliyon 6(8), e04603 (2020)

15. M. Jamzad, M.K. Bidkorpeh, J. Nanostruct. Chem. 10(3), 193 (2020)

16. H.S. Devi, M.A. Boda, M.A. Shah, S. Parveen, A.H. Wani, Green Process. Synth. 8(1), 38 (2019)

17. H. Muthukumar, M. Matheswaran, ACS Sustain. Chem. Eng. 3(12), 3149 (2015)

18. M. Martínez-Cabanas, M. López-García, J.L. Barriada, R. Herrero, M.E.S. de Vicente, Chem. Eng. J. 301, 83 (2016)

19. G.B. Jegadeesan, K. Srimathi, N.S. Srinivas, S. Manishkanna, D. Vignesh, Biocatal. Agric. Biotechnol. 21, 101354 (2019)

20. T. Wang, X. Jin, Z. Chen, M. Megharaj, R. Naidu, Sci. Total Environ. 466, 210 (2014)

21. H.K. Farshchi, M. Azizi, M.R. Jaafari, S.H. Nemati, A. Fotovat, Biocatal. Agric. Biotechnol. 16, 54 (2018)

22. B. Desalegn, M. Megharaj, Z. Chen, R. Naidu, Heliyon 5(5), e01750 (2019)

23. K.S.V. Gottimukkala, R.P. Harika, D. Zamare, J. Nanomed. Biother. Discov. 7, 151 (2017)

24. P. Karnan, A. Anbarasu, N. Deepa, R. Usha, Int. J. Curr. Pharm. Res. 10(3), 11 (2018)

25. P.C. Nagajyothi, M. Pandurangan, D.H. Kim, T.V.M. Sreekanth, J. Shim, J. Clust. Sci. 28(1), 245 (2017)

26. H.K. Handral, A. Pandith, S.D. Shruthi, Asian J. Pharm. Clin. Res. 5(4), 5 (2012) 
27. Y. Tachibana, H. Kikuzaki, N.H. Lajis, N. Nakatani, J. Agric. Food Chem. 49(11), 5589$5594(2001)$

28. K. Velsankar, R. Preethi, P.S. Jeevan Ram, M. Ramesh, S. Sudhahar, Appl. Nanosci. 10, $3675(2020)$

29. K. Velsankar, V. Vinothini, S. Sudhahar, M. Krishna Kumar, S. Mohandoss, Appl. Nanosci. 10(10), 3953 (2020)

30. $\quad$ S.P. Rajendran, K. Sengodan, J. Nanosci. 8348507, 7 (2017)

31. S. Kanagasubbulakshmi, K. Kadirvelu, Def. Life Sci. J, 2(4), 422 (2017)

32. K. Velsankar, S. Sudhahar, G. Parvathy, R. Kaliammal, Mater. Chem. Phys. 239, 121976 (2020)

33. J. Suresh, G. Pradheesh, V. Alexramani, M. Sundrarajan, S.I. Hong, Adv. Nat. Sci. Nanosci. Nanotechnol. 9(1), 015008 (2018)

34. K. Velsankar, S. Sudhahar, G. Maheshwaran, M. Krishna Kumar J. Photoch. Photobio. B. 200, 111650 (2019)

35. D.W. Park, K.S. Kim, J. Nanosci. Nanotechnol. 11(8), 7214 (2011)

36. H.S. Devi, M.A. Boda, M.A. Shah, S. Parveen, A.H. Wani, Green Process. Synth. 8(1), 38 (2019)

37. S. Arsalani, E.J. Guidelli, J.F. Araujo, A.C. Bruno, O. Baffa, ACS Sustain. Chem. Eng. 6(11), 13756 (2018)

38. L. Panawala, , Epediaa 3, 1 (2017)

39. M. Premanathan, K. Karthikeyan, K. Jeyasubramanian, G. Manivannan, Nanomedicine 7(2), 184 (2011)

40. G. Sangeetha, S. Rajeshwari, R. Venckatesh, Mater. Res. Bull. 46(12), 2560 (2011) 
41. K. Velsankar, R.M. Aswin Kumar, R. Preethi, V. Muthulakshmi, S. Sudhahar, J. Environ. Chem. Eng. 8(5), 104123 (2020)

42. M. Thiruvengadam, I.M. Chung, T. Gomathi, M.A. Ansari, V.G. Khanna, V. Babu, G. Rajakumar, Bioproc. Biosyst. Eng. 42(11), 1769 (2019)

\section{Figure Captions}

Figure: 1. Synthesis scheme of iron oxide NPs green synthesized by Murraya koenigii leaves extract

Figure: 2. (a) UV-visible, (b) X-ray diffraction pattern, (c) Fourier Transform Infra-Red spectrum, (d) Particle size distribution graph and (e) Magnetization curve of magnetic iron oxide NPs green synthesized by Murraya koenigii leaves extract.

Figure: 3. (a-b) Transmission Electron Micrographs of magnetic iron oxide NPs green synthesized by Murraya koenigii leaves extract at $20 \mathrm{~nm}, 50 \mathrm{~nm}$ scale range and (c) selected area electron diffraction pattern at $1 / 10 \mathrm{~nm}$ scale range.

Figure: 4. Energy dispersive X-ray spectrum of magnetic iron oxide NPs green synthesized by Murraya koenigii leaves extract.

Figure: 5. Energy dispersive X-ray spectrum mapping of magnetic iron oxide NPs green synthesized by Murraya koenigii leaves extract.

Figure: 6. Antimicrobial assay of magnetic iron oxide nanoparticles green synthesized by Murraya koenigii leaves extract on Pseudomonas aeruginosa, Acinetobacter baumannii, Serratia marcescens, Chromobacterium violaceum, Enterobacter aerogenes, Klebsiella penumonia (Gram-negative bacterial cells), Enterococcus faecalis, Staphylococcus aureus (Gram-positive bacterial cells), Candida albicans, Candida tropicalis, Aspergillus niger, and Aspergillus flavus (fungus cells). 
Figure: 7. (a) Antioxidant, (b) Anti-inflammatory and (c) Anti-diabetic assays of magnetic iron oxide nanoparticles green synthesized by Murraya koenigii leaves extract.

\section{Table Captions}

Table: 1. Phytochemical analysis of magnetic iron oxide nanoparticles green synthesized by Murraya koenigii leaves extract.

Table: 2. Percentage of inhibition in antioxidant assay of magnetic iron oxide nanoparticles green synthesized by Murraya koenigii leaves extract.

Table: 3. Percentage of inhibition in anti-inflammatory and anti-diabetic assays of magnetic iron oxide nanoparticles green synthesized by Murraya koenigii leaves extract. 
Table: 1. Phytochemical analysis of magnetic iron oxide NPs green synthesized by Murraya koenigii leaves extract.

\begin{tabular}{ccc}
\hline \multicolumn{3}{c}{ Phytochemicals analysis } \\
& $\begin{array}{c}\text { Aqueous } \\
\text { extract }\end{array}$ & $\begin{array}{c}\text { Ethanolic } \\
\text { extract }\end{array}$ \\
\hline Phytochemicals & + & ++ \\
Flavonoids & - & ++ \\
Steroids & - & - \\
Saponin & - & ++ \\
Alkaloids & + & ++ \\
Terpenoids & + & + \\
Triterpenoids & ++ & + \\
Polyphenol & + & + \\
Anthraquinone & - & + \\
Glycoside & - & + \\
\hline (-) Absent, (+) Present, (++) High concentration.
\end{tabular}


Table: 2. Percentage of inhibition in antioxidant assay of magnetic iron oxide NPs green synthesized by Murraya koenigii leaves extract.

\begin{tabular}{cccccc}
\hline Samples & \multicolumn{5}{c}{ Percentage of Inhibition (\%) } \\
\cline { 2 - 6 } & \multicolumn{5}{c}{ Concentration $(\mu \mathrm{g} / \mathrm{mL})$} \\
& 20 & 40 & 60 & 80 & 100 \\
\hline Iron oxide NPs & $24.04 \pm 0.19$ & $45.17 \pm 0.97$ & $67.19 \pm 0.93$ & $80.06 \pm 0.06$ & $91.17 \pm 0.04$ \\
Ascorbic acid & $20.06 \pm 0.17$ & $40.15 \pm 0.12$ & $59.12 \pm 0.27$ & $75.27 \pm 0.12$ & $85.19 \pm 0.06$ \\
& & & & & \\
\hline
\end{tabular}

\pm performed in triplicate times

Table: 3. Percentage of inhibition in anti-inflammatory and anti-diabetic assays of magnetic iron oxide NPs green synthesized by Murraya koenigii leaves extract. 


\begin{tabular}{cccccc}
\hline & \multicolumn{5}{c}{ Concentration $(\mu \mathrm{g} / \mathrm{mL})$} \\
\cline { 2 - 6 } & 100 & 200 & 300 & 400 & 500 \\
\hline Iron oxide NPs & $24.04 \pm 0.12$ & $45.27 \pm 0.93$ & $57.30 \pm 0.47$ & $70.04 \pm 0.19$ & $89.12 \pm 1.06$ \\
Diclofenac & $19.04 \pm 0.19$ & $39.47 \pm 0.27$ & $51.02 \pm 0.93$ & $64.17 \pm 0.33$ & $79.99 \pm 1.04$ \\
sodium & & & & & \\
\hline Iron oxide NPs & $24.93 \pm 0.33$ & $35.19 \pm 0.35$ & $45.06 \pm 1.12$ & $59.37 \pm 0.39$ & $75.06 \pm 0.99$ \\
Acarbose & $19.12 \pm 0.19$ & $29.04 \pm 0.37$ & $37.17 \pm 0.17$ & $49.93 \pm 0.93$ & $69.99 \pm 0.97$ \\
& & & & & \\
\hline
\end{tabular}

\pm performed in triplicate times 


\section{Figures}

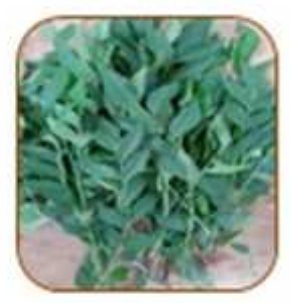

Murraya koenigii leaves
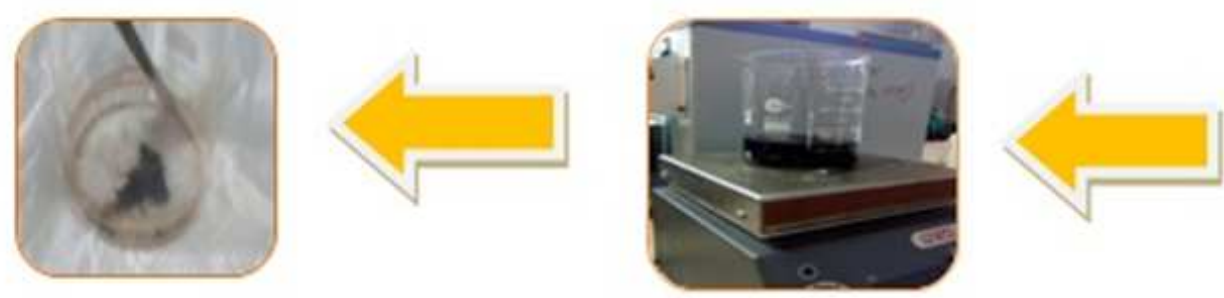

Preparation of extract
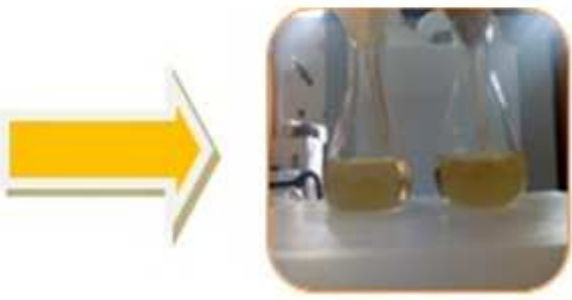

Murraya koenigii leaves extract

Iron oxide NPs

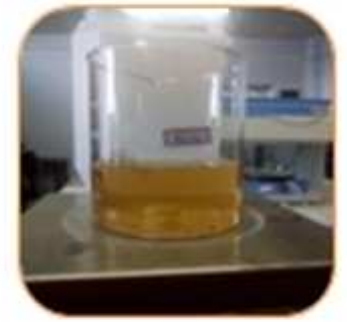

Ferric chloride solution

Figure 1

Synthesis scheme of iron oxide NPs green synthesized by Murraya koenigii leaves extract 

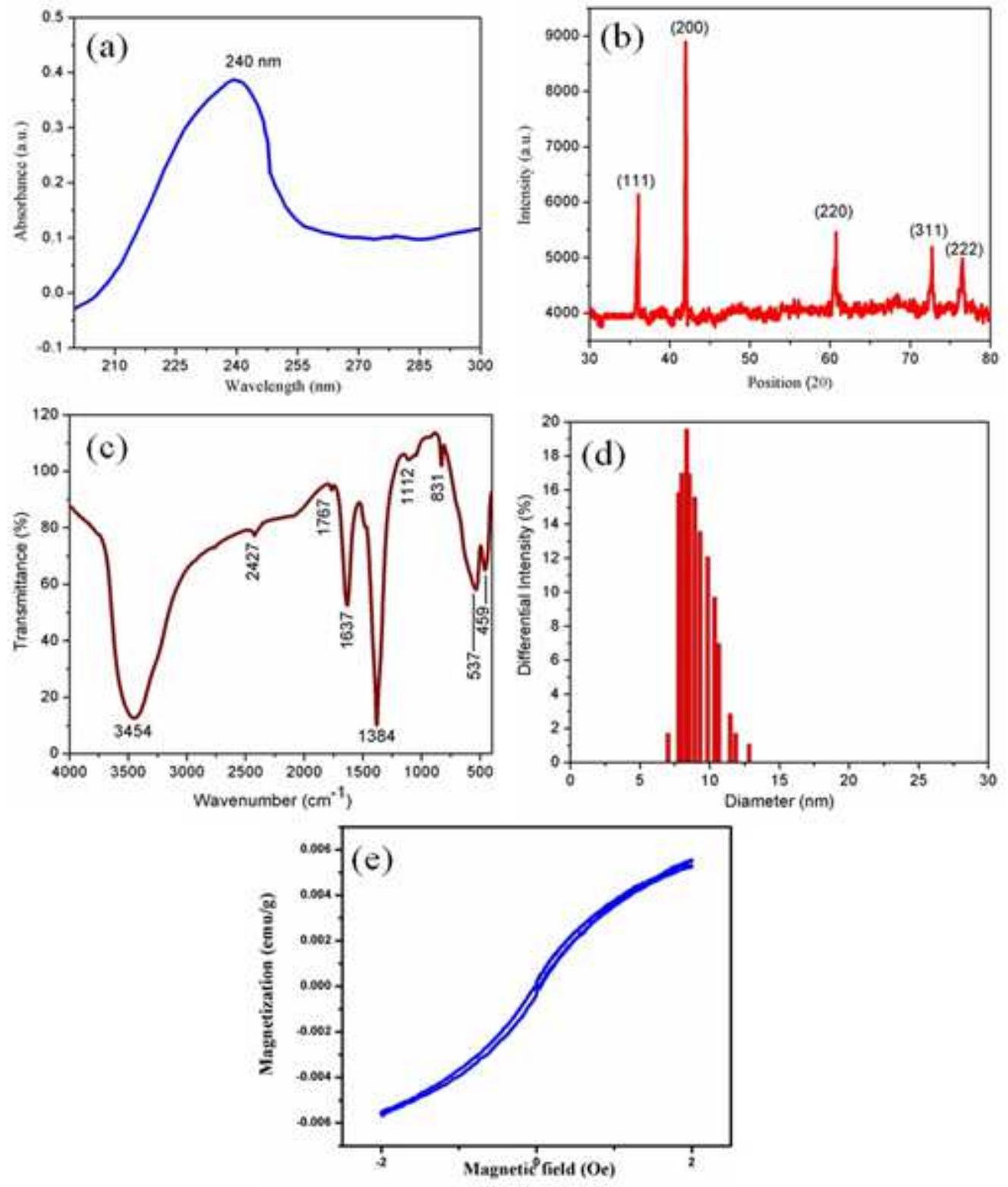

Figure 2

(a) UV-visible, (b) X-ray diffraction pattern, (c) Fourier Transform Infra-Red spectrum, (d) Particle size distribution graph and (e) Magnetization curve of magnetic iron oxide NPs green synthesized by Murraya koenigii leaves extract. 

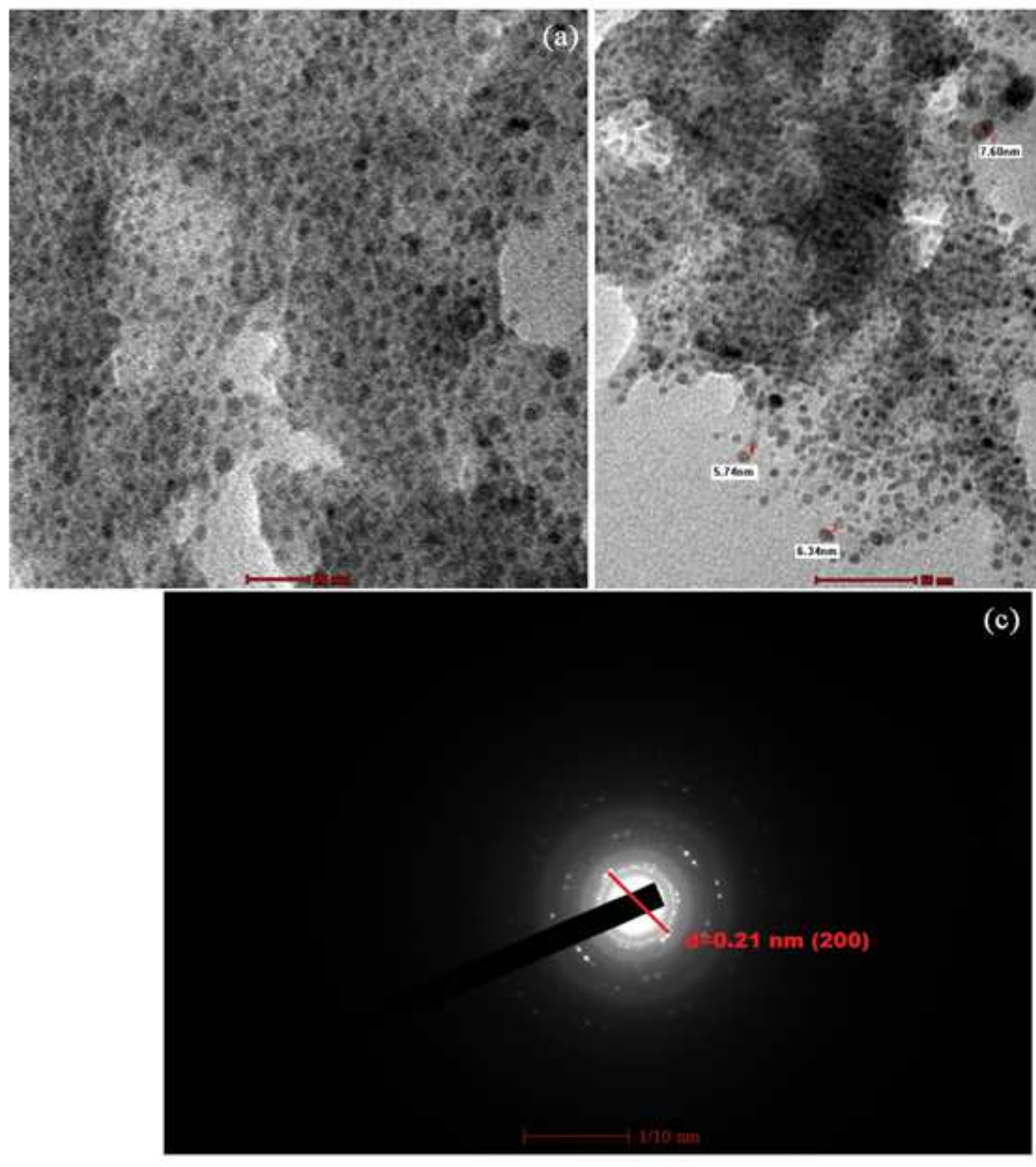

\section{Figure 3}

(a-b) Transmission Electron Micrographs of magnetic iron oxide NPs green synthesized by Murraya koenigii leaves extract at $20 \mathrm{~nm}, 50 \mathrm{~nm}$ scale range and (c) selected area electron diffraction pattern at $1 / 10 \mathrm{~nm}$ scale range. 


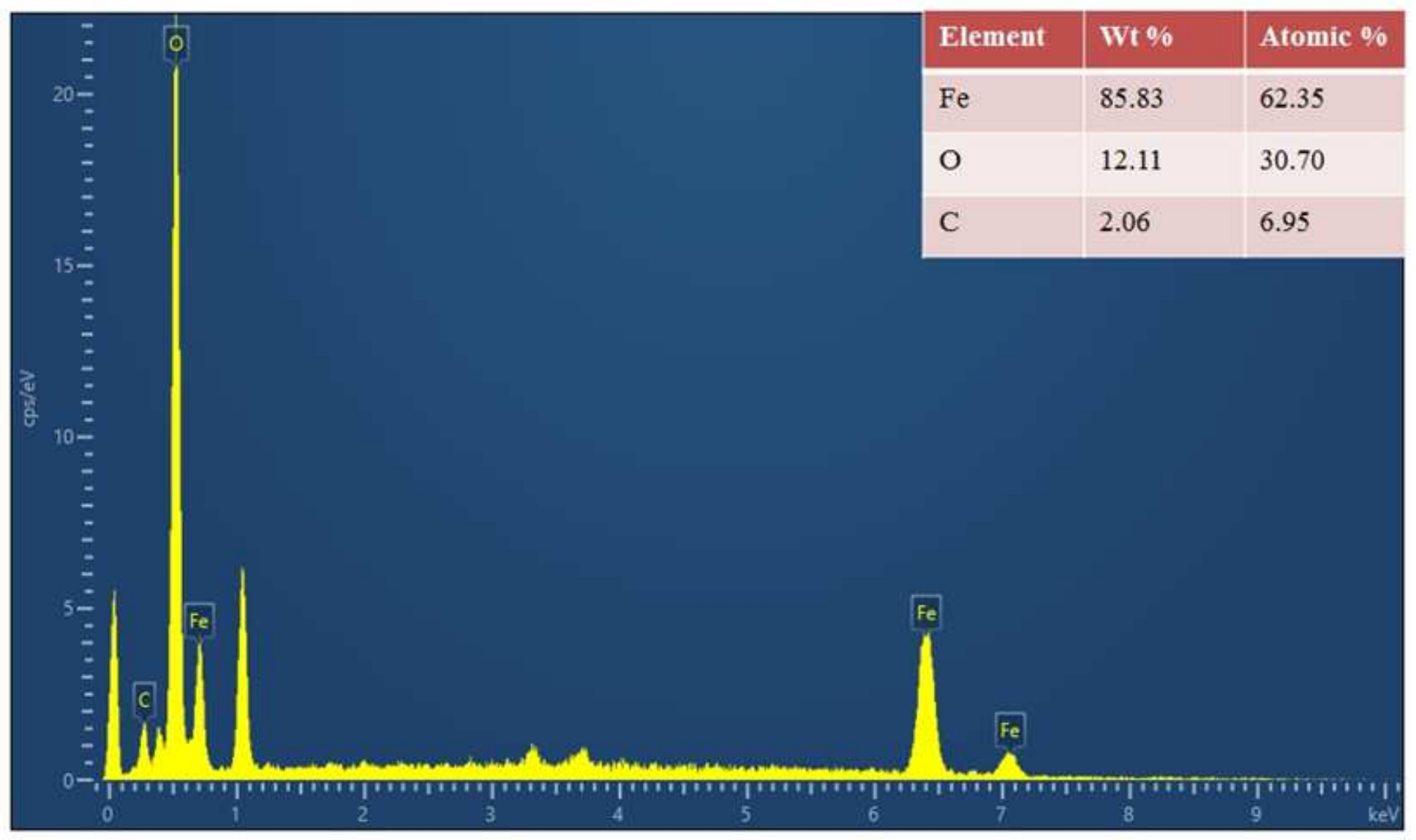

Figure 4

Energy dispersive X-ray spectrum of magnetic iron oxide NPs green synthesized by Murraya koenigii leaves extract. 


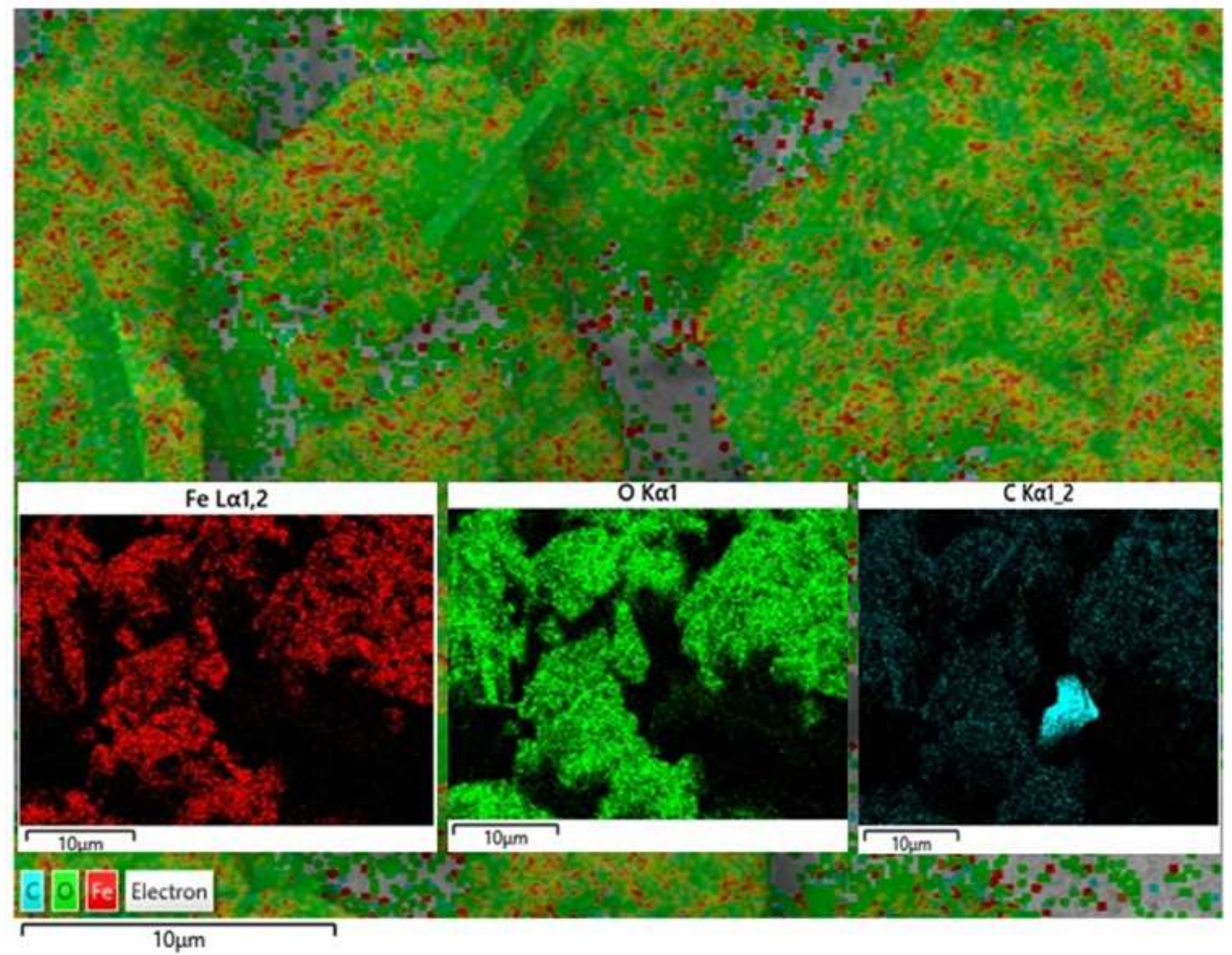

Figure 5

Energy dispersive X-ray spectrum mapping of magnetic iron oxide NPs green synthesized by Murraya koenigii leaves extract. 


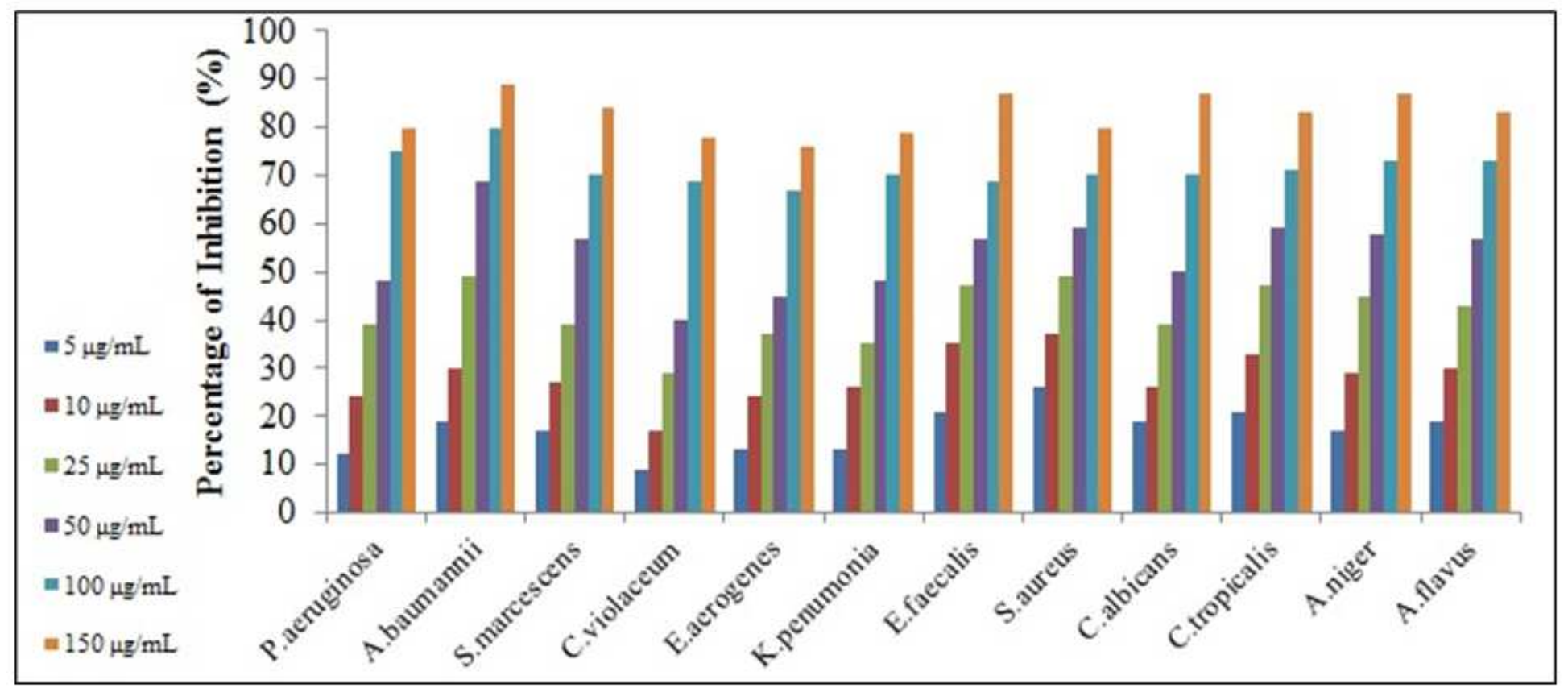

Figure 6

Antimicrobial assay of magnetic iron oxide nanoparticles green synthesized by Murraya koenigii leaves extract on Pseudomonas aeruginosa, Acinetobacter baumannii, Serratia marcescens, Chromobacterium violaceum, Enterobacter aerogenes, Klebsiella penumonia (Gram-negative bacterial cells), Enterococcus faecalis, Staphylococcus aureus (Gram-positive bacterial cells), Candida albicans, Candida tropicalis, Aspergillus niger, and Aspergillus flavus (fungus cells). 

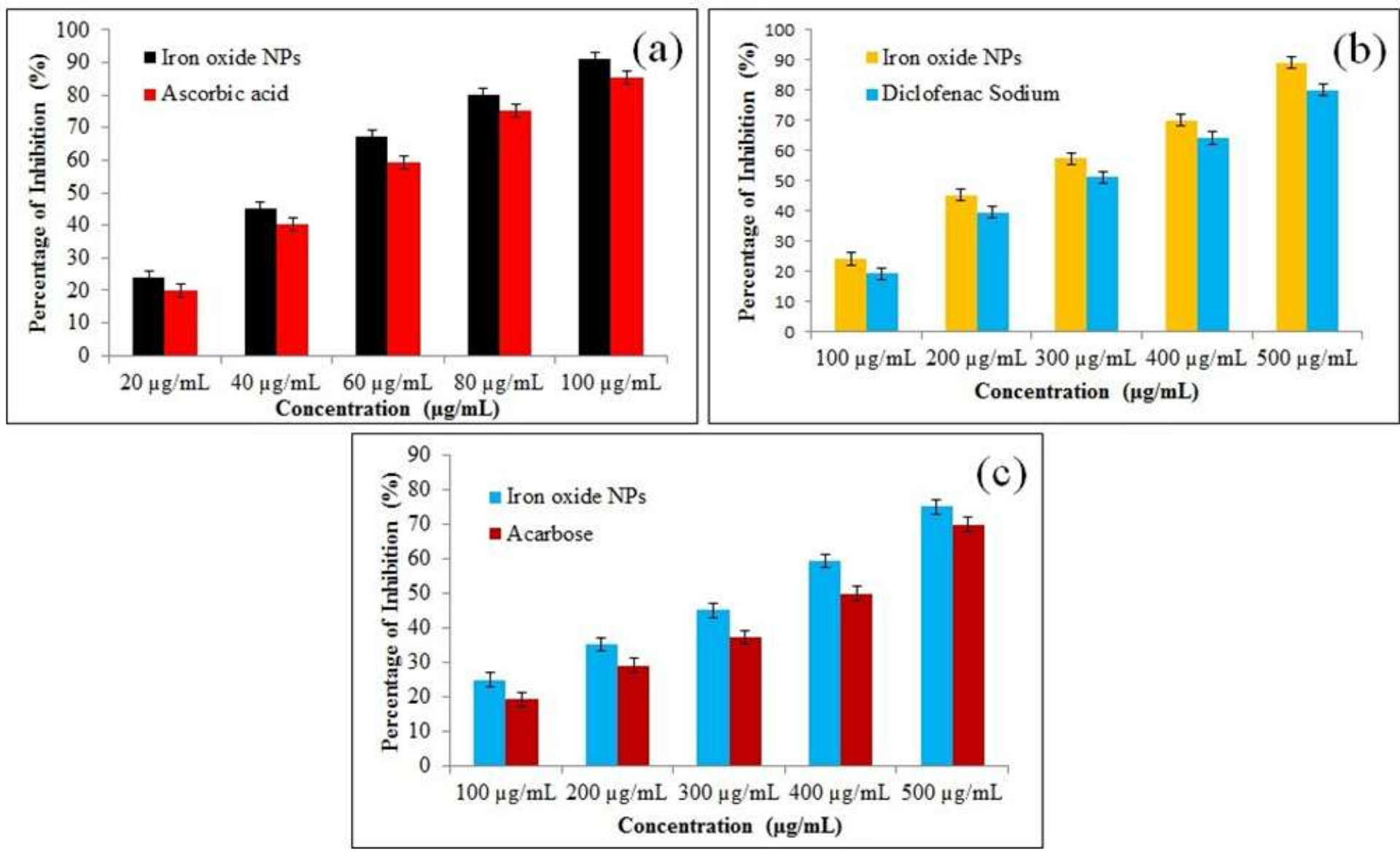

\section{Figure 7}

(a) Antioxidant, (b) Anti-inflammatory and (c) Anti-diabetic assays of magnetic iron oxide nanoparticles green synthesized by Murraya koenigii leaves extract. 